\title{
DNA-based biosensor for the electrocatalytic determination of antioxidant capacity in beverages
}

\author{
M.F. Barroso, N. de-los-Santos-Álvarez, M.J. Lobo-Castan ón, A.J. Miranda-Ordieres, \\ C. Delerue-Matos, M.B.P.P. Oliveira, P. Tuñón-Blanco
}

\begin{abstract}
A B S TRACT
\end{abstract}

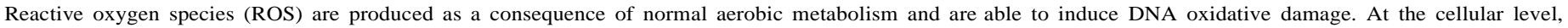

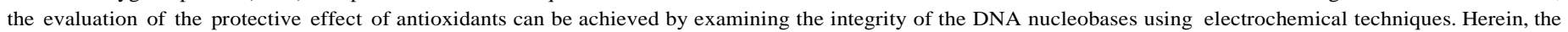

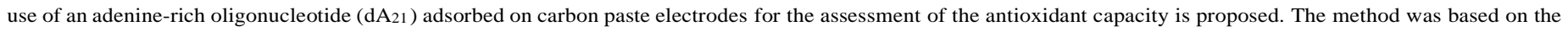

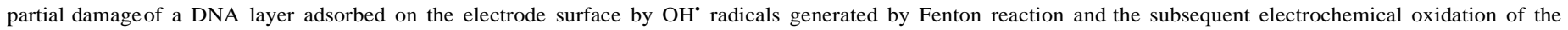

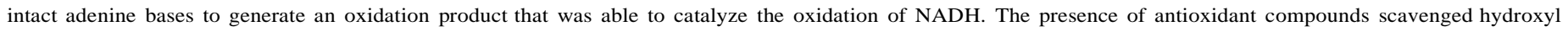

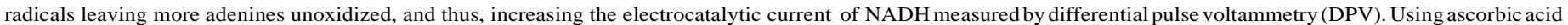

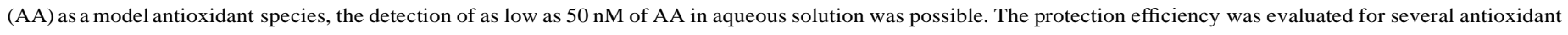
compounds. The biosensor was applied to the determination of thetotal antioxidant capacity (TAC) in beverages.

Keywords:

NADH,DNA biosensor, Electrocatalytic oxidation, Total antioxidant capacity (TAC), Ascorbic acid, Reactive oxygen species(ROS)

\section{Introduction}

Oxidative lesions in DNA are the primary risk factor for gene mutations, which plays a key role in carcinogenesis and aging (Freidman and Heller, 2004). Reactive oxygen species (ROS) are continuously generated in living cells, such as, in the inner mitochondrial membrane, outer membrane, and in several metabolic pathways in mammalian cells, for instance, in the microsomal electron transport. Hydroxyl radical, $\mathrm{OH}^{*}$, is one of the most pow- erful oxidant known in a biological setting, and upon formation, it oxidizes indiscriminately and site-specifically any biomolecule (Laranjinha, 2009). In living systems, most of the hydroxyl radi- cals are generated from the metal (M) ion-dependent breakdown of hydrogen peroxide. In the presence of reduced transition metal ions, e.g. ferrous or cupric ions, hydrogen peroxide is turned into $\mathrm{OH}^{*}$ and $\mathrm{OH}^{-}$through a one-electron redox reaction commonly called Fenton reaction (Eq. (1)) (Mello et al., 2006). The Fenton chemistry is important because it is involved in oxidative damage in vivo leading to changes in DNA that induce mutagenesis, and eventually, carcinogenesis:

$\mathrm{H}_{2} \mathrm{O}_{2}+\mathrm{Fe}^{2+} \rightarrow \mathrm{OH}^{\cdot}+\mathrm{OH}^{-}+\mathrm{Fe}^{3+}$

Most living organisms have developed complex endogenous and exogenous antioxidant systems to counteract and prevent the deleterious effects of ROS. Antioxidants act as reductants agents (free radical terminators), metal chelating and singlet oxygen quenchers (Vertuani et al., 2004). Endogenous antioxidant sys- tems include enzymes, such as, superoxide dismutase, glutathione peroxidase, glutathione reductase, glutathione-S-transferase and catalase (Huang et al., 2005). An additional protection can be pro- vided by exogenous antioxidant compounds, such as, vitamins (A, E, C, $>$-carotene), phenolic compounds, minerals ( $\mathrm{Se}, \mathrm{Zn}$ ) or pro- teins (transferrin, ceruloplasmin, albumin). Foodstuffs constitute an excellent exogenous source of natural antioxidants. It is well- known that vegetables, fruits, wholegrain and some beverages (tea, juice, wine) are rich in many antioxidant and bioactive com- pounds. Recently, to answer to consumer's preferences, flavoured waters produced from mineral and spring waters were developed and commercialized. In the first semester of 2009, 6.23 million litters of this kind of water were consumed by Portuguese pop- ulation (ANIRSF, 2009). This kind of water consists of the addition of flavours, juices and sugar or sweeteners that provide water with 
singular tastes and aromas appreciated by consumers. Considering that flavours/aromas are fruit extracts, they contain natural antiox- idants, transferring them to the bottled water. So, drinking this type of water can increase the daily intake of natural exogenous antioxidants or may contribute to the protective system against ROS.

Several methods have been reported to evaluate the total antioxidant capacity (TAC) in biological and food samples, defined as the moles of a given free radical scavenged by a sample solu- tion disregarding the antioxidant present (Mello and Kubota, 2007). These methods rely on the inhibition of the oxidation of a suit- able substrate by the antioxidant agent. After reaction, the extent of the oxidation is measured at a fixed time by UV-vis spectrom- etry, chemiluminescence, fluorescence and after chromatographic separation (Sanchez-Moreno, 2002).

The protective effect of antioxidants at a cellular level could only be achieved by monitoring the DNA integrity. In recent years, several electrochemical DNA-based sensors have been developed in order to assess the antioxidant capacity (Labuda et al., 2002, 2003; Mello and Kubota, 2007; Qian et al., 2010). UV irradiation (Liu et al., 2005) or most commonly Fenton reaction were used for

$\mathrm{OH}^{*}$ generation. Recently, a ruthenium complex was also used as an electrogenerated oxidant to cause the oxidation of DNA in the presence of $\mathrm{TiO}_{2}$ nanoparticles (Liu et al., 2006).

Taking advantage of the two main lesions caused by ROS in DNA, two detection estrategies have been proposed. On one hand, the use of redox active dsDNA intercalators allowed evaluating the oxidative damage on dsDNA layers because of a significant decrease in the current intensity of the intercalator upon strand scission (Labuda et al., 2002, 2003; Liu et al., 2005). On the other hand, the intrinsic electroactivity of DNA can be exploited. The oxidation of nucleobases on solid electrodes, mainly guanine, and also adenine in a lesser extent, allowed the use of their decreasing oxidation current after damage on carbon electrodes (Mello et al., 2006; Qian et al., 2010).

In this work, an electrocatalytic voltammetric method to assess TAC using DNA-modified carbon paste electrodes (CPE) was devel- oped. It has been reported that the electrochemical oxidation of both adenine and guanine homopolynucleotides in neutral or alka- line conditions led to the formation of a common oxidized product that catalyzed the oxidation of NADH (de-los-Santos-Alvarez et al., 2007). Therefore, the oxidative lesions generated after immersion of the DNA-CPE in the Fenton mixture were indirectly quantified after the electrochemical oxidation of the adenines that remained unoxidized on the electrode surface. The increase of this electro- catalytic current in the presence of several antioxidant species was studied. The biosensor developed was applied to the determina- tion of TAC in several beverages and the results were compared with those attained using other methodologies to obtain an overall picture of the antioxidant profile.

\section{Materials and methods}

\subsection{Chemicals}

Deoxyadenylic acid oligonucleotide $\left(\mathrm{dA}_{21}\right)$ was purchased as a desalted product from Sigma-Genosys (London, UK). Concen- trated saline sodium phosphate EDTA (20× SSPE; $0.2 \mathrm{~mol} \mathrm{l}^{-1}$ sodium phosphate, $2 \mathrm{~mol} \mathrm{l}^{-1} \mathrm{NaCl}, 0.02 \mathrm{~mol} \mathrm{l}^{-1}$ EDTA), tris-HCl

$\mathrm{pH}$ 9.0, phosphate buffer $\mathrm{pH}$ 9.0, iron (II) sulphate heptahydrate, hydrogen peroxide $(30 \%, \mathrm{w} / \mathrm{v})$, gallic acid, resveratrol, nicotinamide adenine dinucleotide disodium salt, reduced form (NADH), were acquired from Sigma-Aldrich (Spain). 1(+)-Ascorbic acid was from Riedel-de-Haën. Caffeic acid, and trolox (6-hydroxy-2,5,7,8tetramethylchroman-2-carboxylic acid, a water-soluble derivative of vitamin E) were from Fluka (Spain). Other chemicals employedwere of analytical grade.

Stock solutions of $1 \mathrm{~g} \mathrm{l}^{-1} \quad \mathrm{dA}_{21}$ were stored at $4{ }^{\circ} \mathrm{C}$ and diluted with $2 \times$ SSPE buffer solution (prepared by dilution of $20 \times$ SSPE solution) prior to use. Fenton solution (generation of hydroxyl radical) was prepared by mixing $\mathrm{Fe}^{2+}$ :EDTA: $\mathrm{H}_{2} \mathrm{O}_{2}\left(1 \mu \mathrm{mol} 1^{-1}: 2 \mu \mathrm{mol}\right.$ $1^{-1}: 40 \mu \mathrm{mol} \mathrm{l}^{-1}$ ) in the molar ratio of 1:2:40.

Mello et al., 2006 reported that when an excess of hydrogen per-oxide was added in the reaction a high DNA damage was obtained. EDTA was added for solubility reasons. All solutions were prepared with water purified with a Direct-Q (Millipore) system.

\subsection{Instrumentation}

Cyclic voltammetry (CV) and differencial pulse voltammetry (DPV) were performed with a $\mu$ Autolab II controlled by GPES software, version 4.8 (EcoChemie, The Netherlands). A conventional three-electrode cell was used, which included a home-made CPE $(3 \mathrm{~mm}$ in diameter) as a working electrode, a platinum wire counter electrode and a $\mathrm{Ag}|\mathrm{AgCl}| \mathrm{KCl}_{\text {sat }}$ reference electrode to which all potentials were referred. The CPE was prepared by mixing $1.8 \mathrm{~g}$ of paraffin oil as a pasting liquid with $5 \mathrm{~g}$ of spectroscopic grade graphite powder (Ultracarbon, Dicoex, Spain). The unmodified car- bon paste was introduced into the well of a teflon electrode body provided by a stainless steel piston. The surface was smoothed against a plain white paper while a slight manual pressure was applied to the piston. Unless otherwise stated, after each experi- ment, the $\mathrm{CP}$ was discarded and a new electrode surface was freshly prepared.

\subsection{Assay procedure}

Unless otherwise mentioned, most experiments consisted of four steps: DNA immobilization, damage of oligonucleotide by the immersion of DNA-CPE on the Fenton mixture and study of the effect of the presence of antioxidants in the system; electro- oxidation of the remaining unoxidized adenines on the CPE, and detection in a $\mathrm{Ca}^{2+}$ containing-NADH solution

DNA immobilization was performed by dry adsorption placing a $5-\mu 1$ droplet of $\mathrm{dA}_{21}\left(180 \mathrm{mg} \mathrm{l}^{-1}\right)$ in $2 \times$ SSPE solution on the elec- trode surface and evaporating it to dryness under a stream of warm air.

DNA damage was carried out by immersing the modified elec- trode in a freshly prepared Fenton mixture in the absence or the presence of antioxidant in $2 \times$ SSPE buffer.

After a fixed period of reaction time, the DNA-CPE was washed with water and immediately immersed in a $0.1 \mathrm{~mol}^{-1}$ phosphate buffer $(\mathrm{pH}$ $9.0)$ to carry out the electro-oxidation of the remaining unoxidized adenine bases. A hundred potential scans were performed between -0.2 and $+1.4 \mathrm{~V}$ at $500 \mathrm{mV} \mathrm{s}^{-1}$ to ensure a com-plete oxidation.

For detection, the DNA-CPE was placed in a NADH solution $(0.5$ mmol $1^{-1}$ in $0.1 \mathrm{~mol}^{-1}$ tris- $\mathrm{HCl} \mathrm{pH} 9.0$ containing $0.01 \mathrm{~mol}^{-1} \mathrm{CaCl}_{2}$ ). The electrocatalytic current of NADH was obtained by sweeping the potential between $-0.2 \mathrm{~V}$ and $+0.5 \mathrm{~V}$ at $50 \mathrm{mV} \mathrm{s}^{-1}$ when $\mathrm{CV}$ was used as a detection technique. For DPV experiments, the potential was swept from -0.2 to $+0.3 \mathrm{~V}$. The step potential was $0.005 \mathrm{~V}$ and the modulation amplitude $0.05 \mathrm{~V}$.

\subsection{Samples and alternative methods description}

Two lemon sparkling flavoured water samples corresponding to two different brands were collected in a supermarket and stored inthe dark at $+4{ }^{\circ} \mathrm{C}$. Sonication was used to eliminate gas from the sample. A lemon flavour used in the formulation of some water brands, was also analysed. This flavour had no description about 


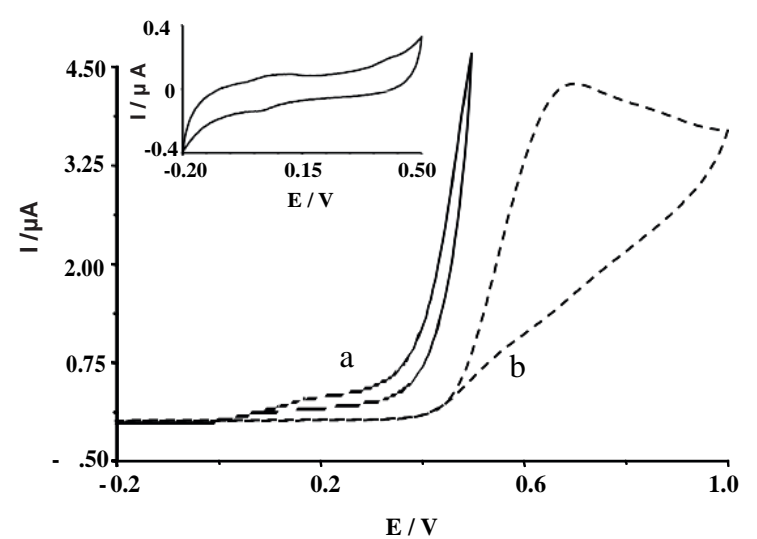

Fig. 1. CVs obtained at $50 \mathrm{mV} \mathrm{s}^{-1}$ in tris- $\mathrm{HCl} \mathrm{pH} 9.0$ in the presence of $0.5 \mathrm{mmol} \mathrm{l}^{-1} \mathrm{NADH}+$ $0.01 \mathrm{~mol} \mathrm{l}^{-1} \mathrm{CaCl}_{2}$ with (solid line) a DNA-CPE and (dotted line) a bare CPE after electrochemical oxidation up to $1.4 \mathrm{~V}$ at $500 \mathrm{mV} \mathrm{s}^{-1}$. Inset: $\mathrm{CV}$ obtained witha DNA-CPE at $50 \mathrm{mV} \mathrm{s}^{-1}$ in tris- $\mathrm{HCl} \mathrm{pH} 9.0$ in the absence of $\mathrm{NADH}+\mathrm{CaCl}_{2}$ solution after identical electrochemical oxidation.

their chemical or aroma composition, only knowing that they are present in some brands of flavoured water.

Label information from brand A indicated the presence of vita- min C, some preservatives, such as, sodium benzoate, potassium sorbate and the acidifying regulator citric acid. Label from brand B sample indicated the presence of green tea and citric acid.

In order to compare the results obtained with the DNA based sensor developed, the total phenolic contents (TPC) of these sam-ples was determined by a colorimetric assay based on procedures previously described (Singleton and Rossi, 1965). Folin-Ciocalteu reagent was used, and the reduced phenols produced a stable blue product at the end of reaction and the results were given as mil-

ligram of gallic acid $1^{-1}$.

Other two methods were used to obtain a complete profile of the antioxidant capacity. The radical scavenging ability of these samples was tested by DPPH (1,1-diphenyl-2-picrylhydrazyl) sta-

ble radical assay (Hatano et al., 1988) and reducing power method (Oyaizu, 1986). DPPH values were expressed in $\mathrm{mg}$ trolox $\mathrm{l}^{-1}$ and reducing power in $\mathrm{mg}$ of gallic acid $\mathrm{l}^{-1}$. A comprehensive study on the chemistry behind these methods has been reviewed (Huang et al., 2005).

\section{Results and discussion}

Previous studies reported by our group indicated that the electrooxidation of different adenine nucleosides and nucleotides, such as adenosine (de-los-Santos-Álvarez et al., 2001), (dA) 20 (de- los-SantosÁlvarez et al., 2002), SAMe (de-los-Santos-Álvarez et al., 2004), or FAD (de-los-Santos-Álvarez et al., 2005) on pyrolytic graphite electrodes (PGE) or CPE (Alvarez-González et al., 2000) in phosphate buffer ranging from $\mathrm{pH} 7$ to 12 , led to the formation of a diimine species, strongly adsorbed on the electrode surface. The common oxidized compound exhibits a quasi-reversible redox pro- cess at low potentials and is able to efficiently catalyze the oxidation of NADH reducing the overpotential by more than $300 \mathrm{mV}$.

The oxidizability of purine bases in DNA depends, predominantly, on the secondary structure of the polynucleotide. Accordingly, ssDNA leads to higher oxidation currents than dsDNA because of their flexibility and better accessibility of nucleobases to the electrode surface (de-los-Santos-Álvarez et al., 2002). Since polynucleotides strongly adsorb on carbon electrodes, the oxida- tion of a layer of $\mathrm{dA}_{21}$ was carried out after physical adsorption of the ssDNA on the electrode surface. The oxidation of adenine bases in DNA takes place at about $1.2 \mathrm{~V}$ at CPE. In Fig. 1 (inset), the redox process associated to the oxidation products arisen from
$\mathrm{dA}_{21}$ after 100 potential scans at $500 \mathrm{mV} \mathrm{s}^{-1}$ from -0.2 to $+1.4 \mathrm{~V}$ on $\mathrm{CPE}$ is depicted. As anticipated, the redox process has a for- mal potential $\left(E^{\mathrm{o}}\right)$ of $0.035 \mathrm{~V}$, which corresponds to the diimine species. After addition of NADH in the presence of calcium ions,

a great enhancement in the anodic current was observed at low potentials associated to the mediated oxidation of NADH (Fig. 1, curve a). The onset of the electrocatalytic wave appeared at poten- tials as low as $0.010 \mathrm{~V}$ with a plateau at $0.184 \mathrm{~V}$. A further increase in the magnitude of the anodic current at more positive poten- tials was adscribed to the direct uncatalyzed oxidation of NADH at CPE, as it is shown in curve $\mathrm{b}$, where the oxidation of NADH at a bare unmodified CPE $\left(E_{\mathrm{p}}=0.70 \mathrm{~V}\right)$ is depicted. The use of calcium ions has been reported to greatly improve the electrocatalytic cur-

rent of NADH (de-los-Santos-Alvarez et al., 2006; Mano and Kuhn, 1999; Toh et al., 2003). This effect is not completely understood at the molecular level, although it is speculated that divalent cations can effectively counterbalance the negative charge of the catalyst favouring the approach of the negatively charged NADH to form a complex between $\mathrm{NADH}, \mathrm{Ca}^{2+}$ and the catalyst. In addition to this, calcium ions can interact directly with DNA contributing to DNA stabilization and conformation (de-los-Santos-Alvarez et al., 2006).

It is well-known that hydroxyl radicals generated in the close proximity to DNA, can attack both the deoxyribose sugar moi- ety and the nucleobases resulting intermediate radicals, which are precursors of DNA base damage such as base oxidation, sugar fragmentation and DNA strand structural changes (Jaruga and Dizdaroglu, 1996). In order to verify that $\mathrm{OH}^{*}$ generated by a Fenton-type reaction are able to oxidize $\mathrm{dA}_{21}$ on the electrode sur- face, the DNA-CPE was placed in the Fenton mixture for 120 s. After transferring to a phosphate buffer solution ( $\mathrm{pH}$ 9), no redox pro- cess at low potentials was observed. An extended voltammetric scan up to $1.4 \mathrm{~V}$ did not show any oxidation peak at $1.2 \mathrm{~V}$ indicating that, at least, part of the adenine bases were effectively oxidized by the generated radicals. This result suggested that Fenton-generated hydroxyl radicals induced oxidative damage on adenine bases fol- lowing a pathway somehow different from the electrochemical oxidation because the adsorbed compound was not formed or the yield was so low that cannot be detected by $\mathrm{CV}$. At this point it is important to remark that the NADH catalyst generated on the electrode surface after oxidation of adenine residues is not the main oxidation product but only one of the several electrogener- ated products reported so far (Dryhurst and Elving, 1968; Goyal et al., 1991; Goyal and Sangal, 2002).

The damaged DNA-CPE was subjected to the above mentioned procedure to oxidize the remaining undamaged adenine bases and immersed in a $\mathrm{Ca}^{2+}$-containing NADH solution. An apparent electrocatalytic wave was observed with a plateau at about $0.18 \mathrm{~V}$ (Fig. 2, curve a). This current was clearly smaller than that obtained when no Fenton reaction was carried out (Fig. 2, curve b) indicating that only few adenine bases remained unoxidized after exposure to Fenton mixture, confirming the ability of the generated $\mathrm{OH}^{*}$ to partially oxidized the DNA layer. When ascorbic acid was added to the Fenton mixture, an electrocatalytic current higher than that obtained in its absence but smaller than when no Fenton reaction was performed was observed (Fig. 2, curve c). This behaviour was in good agreement with a scavenging effect of the antioxidant that prevented the DNA damage to occur. As a consequence, the number of lesions diminished yielding a larger number of adenine avail- able for electrochemical oxidation. A positive correlation between the partial oxidation of DNA and the concentration of antioxidant species in the tested solution would allow the use of the electro- catalytic current of NADH to evaluate the TAC.

It is worth noting that a common oxidation product for the electrochemical oxidation of both adenine and guanine bases was proposed (de-los-Santos-Alvarez et al., 2007). Therefore, a layer of 


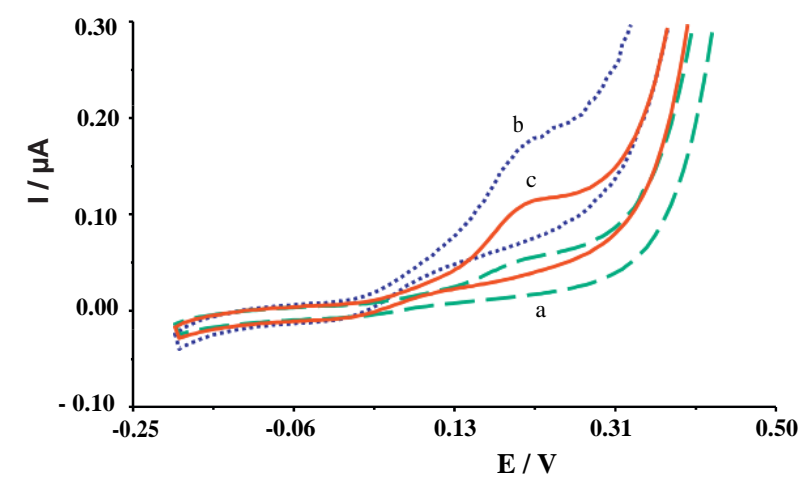

Fig. 2. $\mathrm{CV}$ obtained with a DNA-CPE at $50 \mathrm{mV} \mathrm{s}^{-1}$ in tris- $\mathrm{HCl}$ buffer $\mathrm{pH} 9.0$ in $0.5 \mathrm{mmoll}^{-1} \mathrm{NADH}$ with $0.01 \mathrm{moll}^{-1} \mathrm{CaCl}_{2}$ after: (a) immersion in Fenton solution

and electrochemical oxidation (b) only electrochemical oxidation; (c) immersion in Fenton solution with $10 \mu \mathrm{mol} \mathrm{l}^{-1} \mathrm{AA}$ and electrochemical oxidation.

DNA containing guanine could be also used, in principle, for the preparation of the biosensor layer. However, guanines are the pri- mary nucleobase target for hydroxyl radicals suggesting that the number of intact guanine bases for the subsequent electrochemi- cal oxidation would be smaller than in the case of adenine. Besides, the yield of the catalyst generated from guanine derivatives is much lower than in the case of adenine derivatives (de-los-Santos- Alvarez et al., 2007). Thus, the selection of adenine-rich oligos for the preparation of biosensors seems to be advantageous.

\subsection{Optimization of the experimental conditions}

Firstly, the influence of the number of potential scans to obtain a complete oxidation of the $\mathrm{dA}_{21}$ was studied. It was observed that when increasing the number of potential scans between $-0.2 \mathrm{~V}$ and $+1.4 \mathrm{~V}$ at $500 \mathrm{mV} \mathrm{s}^{-1}$, the amount of catalyst produced also increased, and consequently, an enhancement in the electrocat- alytic current was verified. This increase in the peak current of the catalyst was observed until the 100th scan after that, the amount of catalyst generated reached the highest value (surface coverage

( $\mathrm{I}^{\prime}$ ) of $1.1 \times 10^{-11} \mathrm{~mol} \mathrm{~cm}^{-2}$ ) and remained constant, indicating the

complete oxidation of $\mathrm{dA}_{21}$ adsorbed on CPE. Therefore, this num- ber of

potential scans was chosen for the next optimization steps. Inorderto evaluate the TAConbeverages, some parameters con- cerning the damaging reaction (iron concentration, reaction time between hydroxyl radical and the target molecule) at a fixed con- centration of antioxidant

compound has to be optimized in order to achieve the maximum DNA effect, but without a complete damage. The ratio between the electrocatalytic current obtained after exposing the DNA-CPE electrode to the Fenton mixture in the pres- ence of a fixed amount of antioxidant (ascorbic acid as a model molecule) $\left(I_{\mathrm{a}}\right)$ and the electrocatalytic current obtained in the absence of the antioxidant $\left(I_{\mathrm{d}}\right)$ was selected as a criteria

for opti-

mization. $I_{\mathrm{d}}$ is the minimum value of the electrocatalytic current under each experimental condition because the absence of antiox-idants

in the damaging solution precluded the protection of the nucleobases from radical oxidation, leaving the lowest amount of adenine bases for further electrochemical oxidation. Therefore, the maximum value for this ratio will be selected in each optimization. The level of DNA damage was

evaluated as a function of the vari- ation of the concentration of $\mathrm{Fe}^{2+}$ keeping constant the molar ratio $\mathrm{Fe}^{2+}$ :EDTA: $\mathrm{H}_{2} \mathrm{O}_{2}$ used (1:2:40) (Mello et al., 2006). Fig. 3 shows the effect of $\mathrm{Fe}^{2+}$ concentration (from 1 to $100 \mu \mathrm{moll}^{-1}$ ) on the amount of adenine lesions generated, indirectly evaluated using the electrocatalytic current of the NADH. When increasing the $\mathrm{Fe}^{2+}$ concentration in the absence of antioxidant compound, the electrocatalytic current decreased indicating an increased damaging

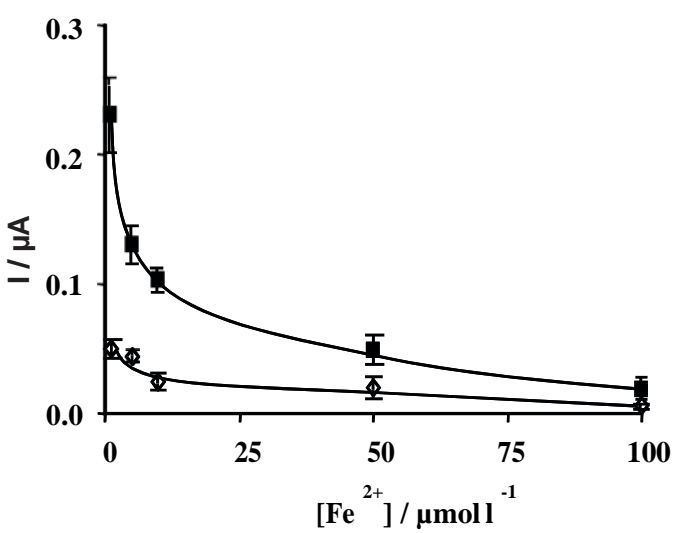

Fig. 3. Influence of $\mathrm{Fe}^{2+}$ concentration (ratio Fe:EDTA: $\mathrm{H}_{2} \mathrm{O}_{2} ; 1: 2: 40$ ) on the electrocatalytic current intensity of $0.5 \mathrm{mmoll}^{-1} \mathrm{NADH}$ with $0.01 \mathrm{moll}^{-1} \mathrm{CaCl}_{2}$ in tris- $\mathrm{HCl}$ buffer at pH9.0.

power attributable to the generation of a higher concentration of ROS. However, when experiments were carried out in the presence of $10 \mu \mathrm{mol}$ $1^{-1}$ ascorbic acid, the scavenging effect was apparent (much higher currents) especially at lower $\mathrm{Fe}^{2+}$ concentrations. From this results it is clear that the protective role of ascorbic acid strongly depended on the concentration of radicals generated, and thus, at high $\mathrm{OH}^{*}$ concentrations, ascorbic acid could not longer pre- ventDNA damage $\left(I_{\mathrm{a}}\right.$ very similar to $\left.I_{\mathrm{d}}\right)$. The maximum value for the

$I_{\mathrm{a}} / I_{\mathrm{d}}$ ratio was obtained at a Fe ${ }^{2+}$ concentration of $1 \mu \mathrm{moll}^{-1}$, which was chosen for further experiments.

Considering that the reaction time between hydroxyl radicals and DNA depends on the half-time of the generated free radicals, this parameter was optimized. The reaction time was studied from 10 to 120 s. In the absence of antioxidant, a decrease in the electro- catalytic current was observed when increasing the incubation time from 10 to $30 \mathrm{~s}$. At longer reaction times the electrocatalytic signal remained almost constant. On the contrary, a continuous increase in the analytical signal when increasing the reaction time in the presence of ascorbic acid was observed. The maximum value for the $I_{\mathrm{a}} / I_{\mathrm{d}}$ ratio was obtained after $120 \mathrm{~s}$, so this time was used in subsequent experiments.

\subsection{Determination of antioxidant capacity}

Foodstuff constitutes an excellent exogenous source of natu- ral antioxidants to counteract and prevent the deleterious effects of ROS. This protective effect is analytically defined as TAC. In this work, ascorbic acid was used as a model antioxidant com- pound. Ascorbic acid is a potent reductant agent that can reduce metal transition ions, thus, a potential pro-oxidant role in vivo was suggested (Podmore et al., 1998). However, most evidences point out to a predominant antioxidant role of ascorbic acid (Carr and Frei, 1999; Evans and Halliwell, 2001). Owing to the fact that DPV is a technique more sensitive than $\mathrm{CV}$, it was used for calibra- tion purposes. The concentration of ascorbic acid was varied from 0.05 to $1.00 \mu \mathrm{mol}^{-1}$. Fig. 4 shows the catalytic current obtained after immersion of the DNA-CPE on Fenton mixtures containing increasing concentrations of ascorbic acid. As expected, the electrocatalytic current of NADH increased when the concentration of ascorbic acid increased up to $1 \mu \mathrm{moll}^{-1}$ because of the availability of a larger number of undamaged adenines for electrochemical oxidation. In the inset, the I measured by DPV was plotted against the concentration of AA. A linear range from 0.05 to $1.00 \mu \mathrm{mol} \mathrm{l}^{-1}$ of AA was found $\left(I(\mathrm{nA})=9.34\left[\mathrm{AA}\left(\mu \mathrm{moll}^{-1}\right)\right]+5.72 ; r=0.995, n=5\right)$. A limit of detection of $50 \mathrm{nmol} 1^{-1}$ was estimated from the regression parameters (concentration at which the analytical signal is equal 


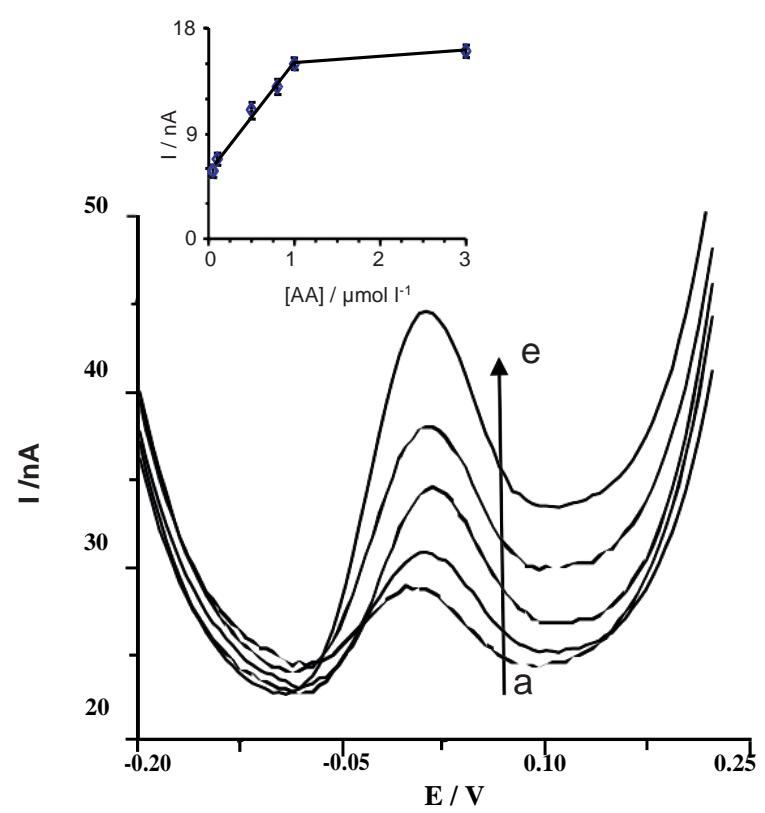

Fig.4. DPVs obtained after immersion of DNA-CPE in Fenton solution containing a standard solution of AA: (a) 0.05 , (b) 0.10 , (c) 0.50 , (d) 0.80 and (e) $1.00 \mu \mathrm{mol} \mathrm{l}^{-1}$.

Inset: relationship between $I_{\mathrm{a}}$ and AA concentration.

to the $y$-intercept plus three times the standard deviation of the regression). The RSD was $3.2 \%$ at $1 \mu \mathrm{moll}^{-1}$.

Zhang et al. (2008) reported the study of DNA damage induced by Fenton system on a glassy carbon electrode (GCE) and its pro- tection with the antioxidant ascorbic acid. These authors verified that ascorbic acid promoted protective effect on the DNA in a nar- row concentration range (from 1.5 to $2.5 \mathrm{mmol}^{-1}$ ) while at lowerconcentrations, a prooxidant role was observed. This behaviour was not observed in our experiments carried out on the electrodesurface and not in solution as in that study. Other recent study also reported the protective effects on the DNA by applying ascorbic acid as a scavenging antioxidant (Nobushi and Uchikura, 2010). Enzyme-modified electrodes using ascorbate oxidase and perox- idase enzymes for the detection of AA showed linear ranges in the submM level (Mello and Kubota, 2007), several orders of magni- tude higher than the exhibited by this DNA-based sensor, which emphasizes the good analytical performance.

Fig. 5 shows a comparison of the efficiency of different antioxi- dant compounds on hydroxyl radical scavenging. The efficiency was expressed as the percentage of the electrocatalytic current accord- ing to the following expression: \% efficiency $=I_{\mathrm{a}} / I_{\mathrm{b}} \times 100$, where $I_{\mathrm{a}}$ is the current intensity measured after DNA damage in the pres-

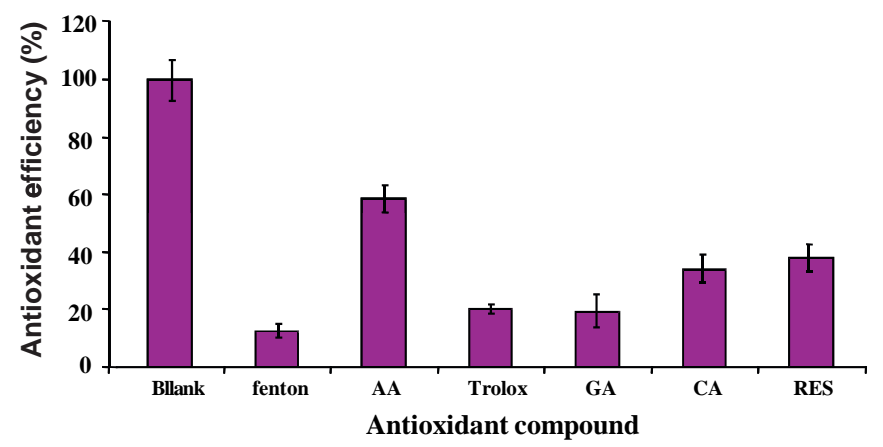

Fig.5. Efficiency of hydroxyl radical scavenging of several antioxidant compounds: AA ascorbic acid; GA - gallic acid; CA - caffeic acid; RES - resveratrol.
Table 1

TAC of flavoured waters.

\begin{tabular}{lcc}
\hline \multirow{2}{*}{ Samples } & \multicolumn{2}{c}{ TAC (expressed in ascorbic acid) } \\
\cline { 2 - 3 } & $\left(\mu \mathrm{mol} \mathrm{l}^{-1}\right)$ & $\left(\mathrm{mgl}^{-1}\right)$ \\
\hline Lemon flavour & $480 \pm 20$ & $85 \pm 4$ \\
Lemon flavoured water & & $0.03 \pm 0.01$ \\
Brand A & $0.19 \pm 0.08$ & $0.50 \pm 0.05$ \\
Brand B & $2.8 \pm 0.3$ & \\
\hline
\end{tabular}

ence of the antioxidant compound and $I_{\mathrm{b}}$ is the electrocatalytic current measured when no damage was done (maximum expected value). The compounds used were ascorbic acid, gallic acid, trolox, caffeic acid, and resveratrol. Using an antioxidant concentration of

$0.5 \mu \mathrm{moll}^{-1}$, it was observed that AA presented the highest protective role among all compounds tested (58.6\%). Hydroxyl radicals had the ability to produce $87.6 \%$ of damage on the $\mathrm{dA}_{21}$ layer. The protective effect of antioxidants ranged from 19.3 to $58.6 \%$. The lowest values were found for gallic acid and trolox, 19.3 and $20 \%$, respectively. Caffeic acid and resveratrol presented a similar protective role of 34.1 and $37.9 \%$, respectively. Using chemilumi- nescence detection, gallic acid and trolox showed higher protection than AA (Nobushi and Uchikura, 2010).

\subsection{Application to TAC assessment in beverages}

The methodology developed was used to quantify TAC on a lemon flavour and two different brands of lemon flavoured waters samples. A lemon flavour was chosen because this fruit is an impor- tant source of antioxidants such as vitamin $\mathrm{C}$, phenolic compounds and it is the most commercialised flavour in the world (Orak, 2009; Xu et al., 2010).

For the quantification of TAC in beverages, $5 \mathrm{ml}$ of the flavour water or $20 \mu \mathrm{l}$ of flavour were diluted in $2 \times$ SSPE to a final vol- ume of 10 $\mathrm{ml}$. Then, the DNA-CPE was immersed in the solution and a freshly prepared Fenton solution was added for $120 \mathrm{~s}$. After this period of time the DNA-CPE was washed and immersed in phosphate buffer $\mathrm{pH} 9$ to carry out the electro-oxidation of the remaining unoxidized adenine bases. The detection was carried outin a $\mathrm{Ca}^{2+}$-containing-NADH solution.

In Table 1, TAC values are expressed in ascorbic acid content, both $\mu \mathrm{mol} \mathrm{l}^{-1}$ and $\mathrm{mg}^{-1}$. It was observed that all samples exhib- ited antioxidant activity. As expected, the highest level was found in the flavour because is a concentrated product. Brand B lemon flavoured water presented an order of magnitud higher TAC value than brand A. In fact, water sample from brand B has lemon flavour and also green tea. Green tea is a bioactive compound and con- tains numerous components with antioxidant activity, such as polyphenols (catechins, epicatechin, epigallocatechin) and vita- mins (Cabrera et al., 2006; Neyestani et al., 2009) so, this may explain the high TAC value.

The reducing capacity of samples was measured by the total phenolic content assay (TPC). This parameter is commonly assumed to be equivalent to the antioxidant capacity, so a good correlation is expected (Huang et al., 2005). The TPC level of the flavour and water from brand A and B was 380, 7.2 and $39.7 \mathrm{mg}$ of gallic acid

$1^{-1}$, respectively. As it was expected, the highest TPC values were from lemon flavour. The water sample from brand $\mathrm{B}$ exhibited a higher TPC value than water from brand A, in good agreement with TAC results.

Finally, the DPPH radical scavenging activity and the reducing

power activity were both evaluated. All samples presented DPPH scavenging activity and reducing power activity. DPPH values were $38.9,44.88$ and $41.5 \mathrm{mg}$ trolox $\mathrm{l}^{-1}$ for lemon flavour and water from brand $\mathrm{A}$ and $\mathrm{B}$, respectively. Reducing power activity values for the 
flavour and water samples from brand A and B were 10.7, 3.8 and $9.6 \mathrm{mg}$ of gallic acid $1^{-1}$, respectively. These four different methodologies applied constituted a powerful tool to elucidate a full profile of TACinfood samples.

\section{Conclusions}

The natural electrochemistry of adenine bases was exploited to develop a DNA-based biosensor for the assessment of total antiox- idant capacity in beverages. A layer of $\mathrm{dA}_{21}$ adsorbed on CPE was damaged by hydroxyl radicals generated in a Fenton-type reaction. The remaining unoxidized adenine bases were electrochemically oxidized to give rise to an adsorbed oxidation product that was able to catalyze the oxidation of NADH in the presence of cal- cium ions. Several antioxidant compounds were tested as hydroxyl radicals scavengers exhibiting efficiencies ranging from 19 to 59\%. Ascorbic acid showed the highest protective role, so the DNA-CPE biosensor was used for the detection of this molecule. The biosen- sor developed was disposable and required a very easy, rapid and reproducible preparation. In addition to this, the low detectabil- ity (50 $\mathrm{nM}$ ) allowed its advantageous used for TAC evaluation in foodstuffs as it was sucessfully shown in several beverages.

\section{Acknowledgements}

N.S.A. thanks to MICINN for a Ramón y Cajal contract. M.F.B. is grateful to the Fundação para a Ciência e a Tecnologia for a PhD grant (Grant Number SFRH/BD/29440/2006). This work was co- financed by Projects CTQ2008-02429 and FICYT IB08-087 and the European Regional Development Fund.

\section{References}

Alvarez-González, M.I., Saidman, S.A., Lobo-Castan ón, M.J., Miranda-Ordieres, A.J., Tũ ón-Blanco, P., 2000. Anal. Chem. 72 (3), 520-527.

ANIRSF, 2009. Associação Nacional dos industriais de refrigerantes e sumos de frutos, 2009. Informar $\mathrm{n}^{\circ}$ 27. from the website www.anirs.pt (in 01/06/2010).

Cabrera, C., Artacho, R., Gimenez, R., 2006. J. Am. Coll. Nutr. 25 (2), 79-99. Carr, A., Frei, B., 1999. Faseb J. 13 (9), 1007-1024.

de-los-Santos-Alvarez, N., de-los-Santos-Alvarez, P., Lobo-Castanon, M.J., Lopez, R., Miranda-Ordieres, A.J., Tunon-Blanco, P., 2007. Electrochem. Commun. 9 (8), $1862-1866$.
de-los-Santos-Álvarez, N., de-los-Santos-Álvarez, P., Lobo-Castan ón, M.J., MirandaOrdieres, A.J., Tuñón-Blanco, P., 2005. Anal. Chem. 77 (13), 4286-4289.

de-los-Santos-Álvarez, N., Lobo-Castan ón, M.J., Miranda-Ordieres, A.J., TuñónBlanco, P., 2004. Electroanalysis 16 (11), 881-887.

de-los-Santos-Álvarez, N., Muñ iz-Ortea, P., Montes-Pañ eda, A., Lobo-Castan ón, M.J., Miranda-Ordieres, A.J., Tuñ ón-Blanco, P., 2001. J. Electroanal. Chem. 502 (1-2), $109-117$.

de-los-Santos-Alvarez, P., de-los-Santos-Alvarez, N., Lobo-Castanon, M.J., MirandaOrdieres, A.J., Tunon-Blanco, P., 2006. Biosens. Bioelectron. 21 (8), $1507-$ 1512 .

de-los-Santos-Álvarez, P., Lobo-Castan ón, M.J., Miranda-Ordieres, A.J., TuñónBlanco, P., 2002. Anal. Chem. 74 (14), 3342-3347.

Dryhurst, G., Elving, P.J., 1968. J. Electrochem. Soc. 115 (10), 1014-\&. Evans,

P., Halliwell, B., 2001. Br. J. Nutr. 85, S67-S74.

Freidman, K.A., Heller, A., 2004. J. Am. Chem. Soc. 126 (8), 2368-2371.

Goyal, R.N., Kumar, A., Mittal, A., 1991. J. Chem. Soc. Perkin Trans. 2 (9), 1369-1375.

Goyal, R.N., Sangal, A., 2002. J. Electroanal. Chem. 521 (1-2), 72-80.

Hatano, T., Kagawa, H., Yashura, T., Okuda, T., 1988. Chem. Pharm. Bull. 36, 2090 2097.

Huang, D.J., Ou, B.X., Prior, R.L., 2005. J. Agric. Food Chem. 53 (6), 1841-1856.

Jaruga, P., Dizdaroglu, M., 1996. Nucleic Acids Res. 24 (8), 1389-1394.

Labuda, J., Buckova, M., Heilerova, L., Caniova-Ziakova, A., Brandsteterova, E., Mat- tusch, J., Wennrich, R., 2002. Sensors 2 (1), 1-10.

Labuda, J., Buckova, M., Heilerova, L., Silhar, S., Stepanek, I., 2003. Anal. Bioanal. Chem. 376 (2), 168-173.

Laranjinha, J., 2009. Oxidative stress: From the 1980s to Resent Update in Oxida- tive Stress, Inflammation and Angiogenesis in the Metabolic Syndrome, 1 st ed. Springer.

Liu, J.F., Roussel, C., Lagger, G., Tacchini, P., Girault, H.H., 2005. Anal. Chem. 77 (23), $7687-$ 7694.

Liu, J.F., Su, B., Lagger, G., Tacchini, P., Girault, H.H., 2006. Anal. Chem. 78 (19), $6879-6884$.

Mano, N., Kuhn, A., 1999. Electrochem. Commun. 1 (10), 497-501.

Mello, L.D., Hernandez, S., Marrazza, G., Mascini, M., Kubota, L.T., 2006. Biosens. Bioelectron. 21 (7), 1374-1382.

Mello, L.D., Kubota, L.T., 2007. Talanta 72 (2), 335-348.

Neyestani, T.R., Gharavi, A., Kalayi, A., 2009. Int. J. Food Sci. Nutr. 60, 79-88. Nobushi, Y., Uchikura, K., 2010. Chem. Pharm. Bull. 58 (1), 117-120.

Orak, H.H., 2009. Int. J. Food Sci. Nutr. 60 (3), 266-266.

Oyaizu, M., 1986. Jpn. J. Nutr. 44, 307-315.

Podmore, I.D., Griffiths, H.R., Herbert, K.E., Mistry, N., Mistry, P., Lunec, J., 1998. Nature 392 (6676), 559-559.

Qian, P., Ai, S.Y., Yin, H.S., Li, J.H., 2010. Microchim. Acta 168 (3-4), 347-354.

Sanchez-Moreno, C., 2002. Food Sci. Technol. Int. 8 (3), 121-137.Singleton,

V.L., Rossi, J.A., 1965. Am. J. Enol. Viticult. 16, 144-158.

Toh, C.S., Bartlett, P.N., Mano, N., Aussenac, F., Kuhn, A., Dufourc, E.J., 2003. Phys Chem. Chem. Phys. 5 (3), 588-593.

Vertuani, S., Angusti, A., Manfredini, S., 2004. Curr. Pharm. Des. 10 (14), 1677-1694. Xu, G., Liu, D., Chen, J., Ye, X., Ma, Y., Shi, J., 2010. Food Chem. 106, 545-551.

Zhang, J.J., Wang, B., Li, Y.F., Jia, W.L., Cui, H., Wang, H.S., 2008. Electroanalysis 20 (15), $\quad 1684-1689$. 